\title{
BEHAVIOURAL ECONOMICS OF ORGANIZATION: EMPLOYEES AND MANAGERS
}

\author{
Petr Houdek, Petr Koblovský
}

\section{Introduction}

If you are an economist, you are reading this article without any financial incentive from your employer. It is equally difficult to verify that such activity will contribute to your growth of human capital and increased productivity in research or teaching. (That does not prevent the authors from hoping it will.) The standard economic model, which explains employee's effort only through the wage (determined by productivity), is therefore incomplete. In particular, it does not consider that incentives to work do not have to be monetary; in other words, that there are other things besides the disutility of labour ((Kamenica, 2012) and section 1.3 here). This perspective article aims to make the simple labour economic model more realistic in order to account for the mounting empirical evidence, which might otherwise be dismissed as anomalies. Why do employers pay employees more than their reservation wage? Under what circumstances do workers exert greater level of effort than the contracted one? When does effort decrease in spite of a rising wage (and there being no income effect)? Under what circumstances does yardstick-based remuneration fail?

The answer to these questions does not consist in a mere list of incongruous (and often even opposing) psychological regularities, cognitive biases and heuristics, sometimes presented as a caricature of behavioural economics (as well as of industrial and organizational psychology). This text aims, instead, to record economic agents' behaviour in the traditional economic method - using the usual efficient and coherent system of principles applicable under defined conditions (Barberis, 2013; Rabin, 1998).

The idea of applying behavioural economics to the workplace is supported by the fact that firms will not, in the short run, undertake any optimising corrections: "Rational arbitrageurs cannot easily limit suboptimal corporatefinance decisions, since it is hard to short-sell a CEO or CFO. Quite the opposite occurs: top executives may be entrenched and hard to get rid of. Biases and mistakes in decision-making are thus much more likely to have a persistent and large effect in corporate finance than on asset pricing." (Camerer \& Malmendier, 2007, p. 236).

To shield ourselves from a charge that behavioural economics' findings are based on artificial laboratory experiments (Levitt \& List, 2007), we try to rely on studies using real world data and field experiments (DellaVigna, 2009); not on data from situations involving inexperienced players with weak motivations, mostly students (Henrich, Heine, \& Norenzayan, 2010), which often limit the applicability of such findings to environments as stimulation as companies. Still, laboratory experiments of the labour market do enable the researcher to control variables and causal relations in a way not affordable by another empirical method, so the text does refer to those. Falk and Fehr (2003) or more recently List and Rasul (2011) discuss the limitations of such experiments, especially with regard to unrepresentative composition of participants, insignificant rewards, limited number of observations and non-reproducibility of some real world problems in a designed experiment. Yet they conclude that experiments (laboratory and field) are a very useful complement to standard real world data analysis. They afford us a relatively quick and low-cost insight into the functioning of studied phenomena. Another pragmatic reason for using laboratory studies is the dearth of real world data, for example on shirking employees who have no motivation to reveal their true behaviour.

The article is organised as follows: the first section introduces a simple model of a worker's 
decision and then augments it by some realistic aspects of real workers' decision-making inspired by insights of behavioural economics. The second section concentrates briefly on the specifics of decision-making by company managers.

\section{Worker's Decision}

The standard model of worker's decision exposes worker $i$ to wage $w$ in return for a homogenous product, and she decides how much labour to supply given her marginal disutility of labour, or cost of labour $c\left(e_{i}\right)$ as a function of her effort $e_{i}$; under the usual assumptions, $c\left(e_{i}\right)$ is an increasing and convex function. Worker's output is a function of her effort and abilities (human capital) $s_{i}$, i.e. $x_{i}=f\left(e_{i}, s_{i}\right)+\theta_{i}$ where $\theta_{i}$ are random shock in productivity with distribution $m\left(\theta_{i}\right)$. The company receives the output $x_{i}$ and pays the wage $w\left(x_{i}\right)$ which is either linear in output $w\left(x_{i}\right)=w_{k}+\beta x_{i}$ in case of piece-rate remuneration, or fixed at $w\left(x_{i}\right)=w_{i}$, possibly augmented by an optional bonus $b_{i}$ upon achieving a certain goal $t$, i.e. $\mathrm{w}\left(\mathrm{x}_{\mathrm{i}}\right)=\left\{w_{i}\left|x_{i}<t ; w_{i}+b_{i}\right| x_{i} \geq t\right\}$. Worker's expected utility of labour is then

$$
\begin{aligned}
& U\left(e_{i}, s_{i}, w\right)=\int_{\theta_{i}} u\left(w \left(f\left(e_{i} s_{i}\right)+\right.\right. \\
& \left.\left.+\theta_{i}\right)\right) m\left(\theta_{i}\right) d \theta_{i}-c\left(e_{i}\right) .
\end{aligned}
$$

Leaving out for simplicity the shocks and the exogenously determined human capital effect, the reduced form of expected utility becomes

$$
U\left(e_{i}, w\right)=u\left(w\left(e_{i}\right)\right)-c\left(e_{i}\right) .
$$

Based on this intentionally simple model (Camerer \& Malmendier, 2007), we argue that its components and underlying assumptions do not describe (even in an "as if" mode) workers' behaviour since their decisions employ different mechanisms and are influenced by other important factors. We highlight 4 areas worth incorporating into the standard model (cf. similarly (Bewley, 2007; DellaVigna, 2009, ch. 2.2; Fehr, Goette, \& Zehnder, 2009; Al-Ubaydli \& List, 2016)).

When choosing their effort, workers are not influenced only by the wage level or its change, but also by i) comparison of the wage offer to a reference level (Additionally, the relationship between wage and output is not necessarily linear: low productivity is still possible even at exceptionally high remuneration rates since the stress from worrying about losing such high reward will be reflected in a greater frequency of errors (Ariely, Gneezy, Loewenstein, \& Mazar, 2009)). Such reference level does not have to be a wage in the form of a financial reward; it can also be interpreted as ii) a quality signal of the social relationship between the employer (principal) and the employee (agent). The reward contains elements of mutual reciprocity. As a result, then, employees do not consider the wage to be the only reward, but value also other, iii) "psychological" rewards of employment: intrinsic motivation - which can in some situations be even more powerful. Indeed, monetary rewards can go as far as to crowd out this intrinsic motivation. Eventually we'll also consider here the observation that in case of yardstick competition, i.e. rewards being based on measuring worker's output relative to other workers' output, one needs to consider also iv) social preferences, i.e. cooperative, reciprocal or indeed subversive motives for relationships among employees.

\subsection{Reference-Dependence Decision-Making}

An important contribution of the Prospect Theory (Kahneman \& Tversky, 1979) are referencedependence models which emphasise that economic agents use narrow bracketing and changes against reference points (Köszegi \& Rabin, 2006) rather than final and absolute wealth levels and their marginal changes.

In their seminal paper, Kahneman and Tversky (1979, p. 273) illustrate referencedependent decision making in problems 11 and 12. Consider first the choice: 1,000 has just been given to you and added to whatever you already own. Choose between alternatives A: $50 \%$ chance of getting another 1,000 , or $B$ : $100 \%$ chance of getting 500 .

Now consider an alternative choice: 2,000 has just been given to you and added to whatever you already own. Choose between the alternative C: $50 \%$ chance of losing 1,000 , or D: $100 \%$ chance of losing 500 . Most participants in the experiment chose $B$ in the first case and $C$ in the second ( $84 \%$ and $69 \%$, respectively). Subjects displayed risk aversion on bets with positive payoffs, but exhibited risk-seeking over bets with negative payoffs. Seen from the point of view of the final and total state, however, both sets of bets are identical, $A=(2000,0.5$; $1000,0.5)=C$ and $B=(1500)=D$. 
Preference reversal is a consequence of considering the bet alone without any regard to its impact on possible income, with subsequent revelation of risk aversion. As Kahneman and Tversky put it, "A salient characteristic of attitudes to changes in welfare is that losses loom larger than gains. The aggravation that one experiences in losing a sum of money appears to be greater than the pleasure associated with gaining the same amount," (1979, p. 279). The act of overemphasising losses against equivalent gains is also used to explain the status quo bias (unwillingness to change the current state of things since any change would imply a loss of the current state), or to account for riskier behaviour as long as the decision maker fears a loss vis-a-vis his reference point (Imas, 2016).

When deciding about alternatives, therefore, people discount the level of income (a final state) which already became a part of their expected wealth and does not, according to Prospect Theory, influence their decision in any significant way anymore. Agents evaluate possible alternatives according to how they can move agents' expected wealth away from a reference state. In case of workers' decisions, agents will care not only about wage, but they will also get utility from the difference between current and expected reference wage $w^{r}$ :

$$
U\left(e_{i}, w, w^{r}\right)=u\left(w\left(e_{i}\right)\right)-c\left(e_{i}\right)+\vartheta R\left(w, w^{r}\right),
$$

where

$$
R\left(w, w^{r}\right)=\left\{\begin{array}{l}
r\left(w-w^{r}\right), \text { for } w \geq w^{r} \\
s\left(w-w^{r}\right), \text { for } w<w^{r}
\end{array}\right.
$$

where $r$ is increasing and concave, $s$ is increasing and convex, whereby loss aversion implies that $-s\left(-x_{i}\right) / r\left(x_{i}\right) \approx 2$; and $\vartheta>0$; is a weight showing how much more intensively the agent considers the distance from reference wage compared to the standard utility from ordinary wage level.

There is no single unique way of determining agent's reference wage. Usually it is set at the level of past nominal wage $w^{r}=w_{t-l}$. Loss aversion can then explain workers' unwillingness to accept nominal wage reduction and a relatively stronger willingness to accept hidden reduction of the real wage (Kahneman, Knetsch, \& Thaler, 1986). Employers anticipate this and instead of reducing wages they tend to reduce the number of employees (Bewley, 2007). Nevertheless, the idea of a reference wage as well as the whole concept of a reference point suffer from significant problems associated with trying to ascertain how they are actually determined by economic agents. Worker can arbitrarily consider almost anything to be the reference wage: her reservation wage, average or median wage in the profession or in some field, all can be influenced also by any anticipated (desired) changes. Any applied study must therefore always include a conceptualisation, a model of agents' interpretation of gains and losses in different contexts. The most widely used approach is to use the concept of expectations, meaning that people observe (derived) consumption levels and then consider the difference between expected and actual consumption (Bewley, 2007).

Linda Babcock and George Lowenstein (1997) showed, for example, that when negotiating over wages, teachers' unions were using comparisons to nearby school districts with higher wages, while school councils (their opponents) were making references to nearby schools with lower wages. The difference between these references then correlated with strike intensity ( $8 \%$ of disputes came to a strike, on average, lasting over 2 weeks). And yet these strategies were probably not intentionally and strategically engineered for the negotiation - for neither party was the difference between the reference groups correlated with the number of previous negotiations and therefore with experience. Both sides simply attributed different importance to different aspects of reality, thus producing a difference in expectations about their "correct" reference wage.

The effect of reference wage can be most easily identified on short-term labour supply. New York City cab drivers have to decide every day for how long they are going to offer their services, given the day-to-day variability of demand they face (peaking during bad weather and/or when big conferences and public events are taking place in the city). In the standard model, hours worked should grow in line with any growth in demand for their services (one day's earnings will have only a negligible income effect in the longer run). And yet actual cabbies work less on a demand-heavy day. One of possible explanations suggests that drivers expect a certain income - they have set themselves a specific target (reference) income they want to achieve every day. During 
low demand for their services, then, they work longer hours to reach the target, while during peak demand their referential income is achieved quickly and they only work short hours. Elasticity of hours worked with respect to their earnings is therefore negative (Camerer, Babcock, Loewenstein, \& Thaler, 1997). However, their income can be influenced also by other factors, and the data are also consistent with possible shifts on the labour supply side: the nature of work can worsen during the more intensive days and $c\left(e_{i}\right)$ may grow; see for example (Farber, 2015; Stafford, 2015) for a cautionary note on the generalization of these target earning findings.

Such difficulties in identifying causality are fortunately absent from a field experiment, which rewarded one group of messengers with an expected wage rise of $25 \%$ and their productivity was compared with a similar group whose members did not enjoy a raise. The next month the roles reversed and it was (only) the second group who was given a higher wage. This design allows for measuring the supply side reaction (number of shifts worked and deliveries delivered) to an exogenous increase in the wage rate (Fehr \& Götte, 2007). Messengers did work more shifts (usually lasting 5 hours) in the higher paying month, but they worked less intensively: the average number of delivered packages was lower. This finding is also more consistent with the theory of referential income. Workers are motivated by the higher wage to go to work more often, but achieving their reference income faster they can then reduce their work effort. Another explanation could also be tiredness after an intensive shift, but messengers were also labtested for loss aversion by means of a lottery; messengers who refused a lottery offering 50-50 odds of winning $8 \mathrm{CHF}$ or losing $5 \mathrm{CHF}$ were exactly those who exhibited a reduction of deliveries after wage increase. This again is suggestive of the existence of reference dependent preferences.

Applying equation (3) at a company level implies that even when the final state of the worker's reward is the same, her efforts can differ, depending on whether the reward is offered as an improvement or deterioration relative to a reference point. The influence of framing on productivity was tested in a real field experiment in a Chinese electronics factory Wanlida Group Company (Hossain \&
List, 2012). When employees got a provisional bonus before the start of the workweek but were warned that they would lose it on payday unless they achieve the productivity norm, they worked more productively than employees of a control group who were merely given the standard promise to receive a bonus upon achieving the norm. The effect was relatively small, however; productivity grew by $1 \%$. Interestingly, the effect of framing as a loss was stronger when whole teams were rewarded this way - social pressure came to bear on the less productive tea members. Long-term productivity gains were achieved through bonuses paid by both methods (ex post and ex ante) compared to workers receiving no bonuses at all.

Even though the framing of "reward as loss avoidance" was more effective and led to productivity gains, in some situations workers can interpret the mechanism as a sign of distrust. This brings up a more complex methodological problem: as a researcher one could be trying to model specific situations as part of one and the same scheme-even though the actual decision-making agents can interpret it differently. The incongruence between the actual decision-making mechanism by actual people and the researcher's structural model that describes it then leads to un-predictive models (Hudík, 2012; Rusinova \& Houdek, 2013). In spite of all this, there may be yet another factor acting more strongly than loss aversion: reciprocity (as demonstrated e.g. in Christ, Sedatole and Towry, (2012)).

\subsection{Reciprocity, Employment as a Gift Exchange}

Compared to simple piece-rate remuneration, which clearly states (and enforces) both the product and the reward, actual work contracts are usually highly incomplete since they cannot capture the whole complexity of the job description expected from the worker. There are vague specifications of outcomes, outcomes are either impossible or costly to fully verify and therefore a fixed wage $w\left(x_{i}\right)=w_{i}$ is often specified. All these things, however, enable the worker to shirk, or at least greatly vary her work effort. And on real workplaces shirking is not actually monitored all that much. Akerlof (1982) famously argued that employment contracts should be seen as "exchanges of gifts". The employer gifts the employees a higher-thanreservation wage and (some) employees in 
return gift to the employer a higher effort than the minimum observable requirement.

Under reciprocity, equation (3) applies with the specification that the reference point is higher than the required reservation wage, i.e. $c\left(e_{i} \mid g\right)<0$ since on the one hand the gift $g$ reduces the disutility of work effort, and on the other hand utility is obtained from the reciprocal behaviour towards the employer. Therefore, equation (2) can be reformulated as

$$
\begin{aligned}
& U\left(e_{i}, w\right)=u\left(w\left(e_{i}\right)\right)-c\left(e_{i}(g)\right), \\
& \text { given the expected } \dot{e}_{t}(g)<0 .
\end{aligned}
$$

First field experiments to test this theory were undertaken by List and Gneezy (2006). In one of them day labourers were hired and offered a wage of 12 USD per hour to catalogue books in the library for six hours. First group of such workers really got this reward upon completing the work. The second group, however, was told before the beginning of their work that there is suddenly more money available for wages and that they would receive 20 USD per hour. Productivity of both groups was then analysed. The group getting paid more than originally promised did indeed work much more intensively, to start with. However, over time the effect of the promise evaporated and after the third hour of work their productivity was indistinguishable from workers in the first group. Other studies also imply that in general it is ineffective to pay gifts in the form of higher wages: the initial early boost to production eventually expires and does not cover the extra wage costs as productivity falls quickly over time (Fehr et al., 2009). Most of these studies, however, are testing only one-off temp jobs, which do not allow for building up reputation, a form of firm-specific social capital.

A similar experiment with cataloguing books was also undertaken in Germany, except this time it studied negative reciprocity (Kube, Maréchal, \& Puppe, 2013). A job adverts again promised that workers will get "most probably" 15 EUR. As workers turned up, they were divided into three groups. One was given what was promised, the second one was told it would only get 10 EUR and the third group started working under the impression that they would get 20 EUR. Nobody from the less receiving group actually left; however, their productivity was consistently $20 \%$ below that of the normally-paid workers. Unlike quantity, the quality of their work was unaffected: workers merely reduced their effort instead of outright sabotaging the output. By contrast, the group, which was being paid more than promised was more productive by about $5 \%$, but this was not significant. Physical limits of output were controlled for throughout. Members of the last group were paid piece rate $w\left(x_{i}\right)=w_{k}+\beta w_{i}$ at 0.4 EUR per book. This group consistently achieved $25 \%$ higher productivity.

These results indicate that workers interpret the decision about the wage level as a social interaction, they surmise how justly or unjustly they are being treated by the employers and they react to it reciprocally. Positive reciprocity cools off over time, influence of negative reciprocity persists. Therefore, negative reciprocity is yet another factor explaining the downward rigidity of wages observed in the real world: companies rightly fear revenge activity from workers.

In a follow-up study (Kube, Marechal, \& Puppe, 2012), the original authors adjusted the experimental design in order to test whether workers would be motivated more if they get 7 euros' worth in the form of a physical gift or as a higher monetary reward (compared to the benchmark treatment). Productivity was consistently higher in the monetary-giftrewarded group (the sense of fulfilling one's duty may therefore be stronger in Germans than in Americans), but the effect was insignificant. However, the physical gift of a thermal cup worth 7 EUR elicited a permanent increase (by 30\%) in productivity compared those who were gifted 7 EUR in cash. Physical gift apparently implies good intentions of the employer and therefore a greater increase of commitment than through mere cash. These results indicate that results differ both across countries and across the form of an otherwise equally valued gift.

Evidence from real world labour relations is difficult to get since workers are understandably motivated to hide their true work effort, if they're shirking. Labour market data also do not suggest that positive reciprocity is a strong factor determining labour supply - estimates of elasticity of output with respect to wage changes range from mere 0.07 to 0.38 (Kube et al., 2012). Even more problematic is trying to derive causality from these estimates: workers may be less productive as a result of reciprocal behaviour following a reduction in wages, or they may no longer feel any bond with the company and are looking for a new job which lowers their work discipline, etc. 
There are only a handful of real world studies testing similar behaviour rigorously. Management of one American Bridgestone/ Firestone tires factory wanted to lengthen the shifts from 8 to 12 hours in July 1994 and to lower the wages of new workers. Employees went on strike, which lasted with some adjustments for 2 years; but they partly continued working in the factory - the production was highly dependent on human labour and workers could therefore vent their frustration on the product. Data on car accidents then revealed that tyres produced in that factory over that time period were faultier and contributed to many deadly accidents (271 dead and 800 injured; and one of every 400 tires produced in the factory was returned under warranty). The frustration felt by employees was reflected in the lower quality of work (Krueger \& Mas, 2004).

Similar reaction was identified among New Jersey policemen between 1978 and 1996. After wage negotiations, which did not meet policemen's demands, the rate of crime detection dropped by $12 \%$ compared to periods where their demands were met. There was even a drop in the average number of years of prison time the convicted criminals were getting at trial (suggesting that the policemen had not done their work thoroughly). Additionally, crime rate went up by $6 \%$ after policemen lost their negotiation (Mas, 2006).

\subsection{Extrinsic and Intrinsic Motivation, Crowding Out}

It should by now be obvious that the standard worker's expected utility model is incomplete. As we will show in this section, work effort can even bring positive utility of fulfilling intrinsic motivation, $m$, to some workers (or under some circumstances). If we have $i=\{g\}$ just like in the gift exchange case, we get $c\left(e_{i} \mid i\right)<0$ (Gneezy, Meier, \& Rey-Biel, 2011; Kamenica, 2012). In this framework the workers' effort is not so much influenced by extrinsic motivation such as money or extensive oversight by the employers, it can even be destroyed by them.

Worker's productivity is a function of various aspects of the employer's behaviour, his trustworthiness, his attention to the worker's individuality, his use of symbolic bonuses, intensity of supervision, and so on. Ellingsen and Johannesson (2007) illustrate these points with a case (David Packard's memory of his General Electric's experiences) when excessive control of issued material and tools in a General Electric factory did not lead to a reduction of thefts. On the contrary, theft became chronic since workers interpreted the measure as a sign of distrust and took up stealing from the company as a sport. Still, in general better supervision usually does increase productivity and reduce cheating (Pascual-Ezama, Prelec, \& Dunfield, 2013). It is a regularity, which is likely to be culturally more universal.

Another study made important strides towards our understanding how meaningful workers consider their job to be. An experiment (Ariely, Kamenica, \& Prelec, 2008) divided subjects into three groups which were tasked with simple mechanical job - in random sequences of letters printed on sheets of paper to mark chosen letters (there was a reward of $\$ 0.55$ for finding 10 instances of two consecutive letters ' $s$ '). All workers were rewarded through piece rate, with every successive sheet of paper offering a linearly lowered wage. They were free to stop working at any point. For the first group, the experimenter/supervisor always accepted their marked sheet without even checking it for mistakes. The second group was asked merely to place their marked papers on a growing pile (the experimenter/supervisor ignoring their work). The third group's output was both ignored and destroyed, the experimenter/ supervisor immediately feeding their submitted sheets into a shredder. Although subjects could cheat in their work in all three groups (whereby the risk of discovery was the lowest in the third group), the gross output should not be very different across the groups. In reality the respective average outputs were 9, 6.8 and 6 sheets of paper. In spite of obvious monetary rewards, workers were not ready to participate in meaningless work. We can find an effect similar to "meaningfulness" also in the degree to which a worker identifies with the company and its goals (as demonstrated by "economics of identity" (Akerlof \& Kranton, 2005)).

It seems that monetary reward cannot fully compensate for an intrinsic drive to have a meaningful and fulfilling job. At the same time, as just described, the relationship between the employer and the employee can be founded on trust and reciprocity; any monetary reward or supervision by the employer can weaken these motivations or even crowd them out completely. Productivity can suffer as a result (Gneezy et al., 2011). However, mutual influence of 
individual motivations is not fully predictable and depends on specific context (Vranka \& Houdek, 2015). Even in non-profit organisations operating mostly on the basis of trust and intrinsic fulfilment there are marked increases in efficiency once stringent supervision of activity is introduced (Bengtsson \& Engström, 2013).

\subsection{Relative Remuneration}

Things get more complicated when work effort is influenced by worker's relationships to other co-workers. We shall concentrate here on the effect of remuneration. For effects on firm culture, peer pressure and others, see e.g. (Camerer \& Malmendier, 2007, ch. 7.3).

Data of one British fruit company were used to test several remuneration mechanisms (Bandiera, Barankay, \& Rasul, 2005). The first one, "yardstick competition", set a decreasing piece-rate dependent on the average productivity of all workers (workers' pay depends on the ratio of his/her productivity to average productivity among all co-workers). Under these conditions, workers who consider the well-being of others have an incentive to exert low level of work effort. The second one was a simple piece-rate. Even though the implicit wage was lower, productivity in this group was $50 \%$ higher. It is impossible to distinguish from these results whether workers were being altruistic towards each other or whether they created a cartel against the employer, assuming they could check each other's effort levels. The latter option seems more likely, since for those fruit pickers who could not see each other working there were no differences in productivity under different remuneration mechanisms (moreover Bandiera et al.'s findings thus casts doubt on the income targeting hypothesis).

Other studies on relative remuneration do not yield such clear-cut results. Introduction of relative evaluations, whether in the form of bonuses or sanctions (Kuběna, Houdek, Lindová, Příplatová, \& Flegr, 2014), or the probability of promotion, will make a sabotage of co-workers' labour more attractive (Harbring, Irlenbusch, Kräkel, \& Selten, 2007). Those co-workers in turn, realising the risk of being harmed, may themselves reduce their productivity (Chen, 2003).

On the other hand, workers may be subject to positive social pressure and associated increased productivity. A study of productivity of cashiers in one large American supermarket revealed that augmenting a group of cashiers with one highly productive cashier (who is able to see other cashiers) will increase their productivity. This effect is relatively high; a $1 \%$ more productive observing-cashier will result in a $0.23 \%$ increased productivity of observedcashier. This finding is true even after controlling for possible cooperation between the more and less productive cashiers (such as helping each other out with manually entered codes of unmarked and with un-scannable items) (Mas \& Moretti, 2009; Herbst \& Mas, 2015).

\section{Decision-Making by Managers}

If we said that it is difficult to monitor (or motivate) individual work effort in workers, in managers it is doubly difficult. They may appear to be subject to transparent evaluation criteria in terms of the company's financial health (or share price), but attaching their specific contribution to these aggregates co-influenced by plethora of other factors is very hard indeed.

Equation (2) abstracted from effects of chance or an external shock $\theta_{i}$ on worker's remuneration, $w\left(f\left(e_{i}, s_{i}\right)+\theta_{i}\right)$, though in reality exogenous shocks do indeed affect the output especially of top managers. Not even owners can often identify such influences and set $w_{C E O}\left(f\left(\theta_{i}\right)\right)$. Bertrand and Mullainathan (2001) showed that CEO's reward is also a function of chance or "luck", not just of their own effort: CEOs receive substantial bonuses even in situations when profits come through a positive movement of the exchange rate or through an increase in the world price (e.g. of oil in case of oil company CEOs) - events which they had no way of achieving directly. It has also been shown that CEOs lower their productivity after receiving a prestigious prize for their management skills, and yet continue to be paid even better than before (Malmendier \& Tate, 2009).

Managers often do not admit to (or are unaware of) their own mistakes (Houdek \& Koblovský, 2016; Houdek, 2016) and hold on to unproductive investments or company workflows. This can be explained by the principal-agent problem (the manager-agent has a reputational incentive not to publicise his mistakes since the owner-principal is unlikely to uncover them). But sticking to status quo can also imply avoidance of (psychological) loss that would obtain from admitting a mistake. Pedace and Kiholm Smith (2013) studied managing 
coaches of baseball teams and showed that loss aversion plays a substantial role in their decision-making. When a player of the managed team suffers from low game productivity, he stands a lower risk of being replaced if it was the current coach who originally hired him. Should the coach change, however, the probability of letting go of an unproductive player increases. This can also hardly be attributed to the coach's reputational vested interest since the effect is the same independent of the length of his career and therefore also of his future career prospects. This study therefore nicely highlights the importance of replacing top managers frequently enough to open up the possibility of re-evaluating set procedures and the ability to terminate ineffective ones - now that they are no longer tied with former decisions of current managers.

When supervision by owners-principals is weak, psychological tendencies of managersagents can be even stronger than those of employees. To illustrate the point - even events like the birth of their child influence CEOs' decision-making (Dahl, Dezső, \& Ross, 2012). Danish CEOs increase their own remuneration following the birth of their child (especially if it is a son). Perhaps that is a rational move trying to provide better for the family. But there are signs that they also lower wages to employees, but less severely to women. That may imply increased empathy towards them after their own close encounter with childbirth a psychological motive.

Camerer and Malmendier (2007) summarise other heuristics of managerial behaviour biases in attaching responsibility, in directing effort, etc. Here we shall limit ourselves only to excessive optimism and overconfidence. Two papers (Malmendier \& Tate, 2005; 2008) show that managers overestimate their ability to select successful projects, resulting in investment into excessive variance of different projects as well as in overpriced takeover bids and mergers. Excessive self-confidence was measured by the degree to which CEOs held onto their share options until expiry, in spite of most of them having very under-diversified portfolio (such behaviour would make sense only of a CEO overestimates his ability to "create" high future profitability of the company, assuming away any fraudulent insider-information trading).

Overconfidence and excessive optimism also explains the dependence of company's investment on its available liquidity (and not on availability of credit or on entrepreneurial opportunities, for example). CEOs prefer internal, mentally "cheaper" financing. It is, however, important to interpret these results in the right context, since risk aversion will tend to be lower with CEOs or businesspeople in general, compared with the rest of the population. Equally, self-confidence or optimism will tend to be necessarily higher (Ben-David, Graham, \& Harvey, 2013; Graham, Harvey, \& Puri, 2013).

\section{Conclusions}

Behavioural industrial organisation is a new field and many results of its empirical studies are unique and/or based on specific sectors and contexts. There is no doubt that the low geographic, cultural and legal diversity of sources is a shortcoming of our current state of knowledge. The vast majority of studies use data from Anglo-Saxon (USA, UK) or Germanspeaking (Switzerland, Germany) economies. The intensity of reciprocity of workers still differs greatly even among these developed economies, as we have shown in section 1.2. It remains an open question to what extent one can reproduce the aforementioned results in post-communist, Latin American or Asian countries with different values and legal traditions on the labour market.

It is reasonable to expect that idiosyncrasies of workplace culture, be they sectoral or national, will continue to play an important role. For instance, industrial organisation is influenced also by national levels of interpersonal trust: in countries where people trust each other more, companies have a greater tendency to decentralise decision-making about hiring, production or sales, which leads to a general increase in productivity (Bloom, Sadun, \& Van Reenen, 2012). One culture tolerates not turning up to work for personal reasons, another culture frowns upon it (Parboteeah, Addae, \& Cullen, 2005), and so on. Future empirical work will therefore have to pay an increasing attention to accounting for agents' heterogeneity in preferences, values and ways of decision-making since they all influence subsequent dynamics of companies. See for example the effect of gender composition of teams on their productivity (Hoogendoorn, Oosterbeek, \& Van Praag, 2013), or explaining wage differentials between men and women 
not only with traditional variables but also with preferences for competitiveness, bearing of risk (Croson \& Gneezy, 2009) etc.

Identification of (psychological) regularities in decision-making (including possible errors and biases) of workers and managers will be necessarily followed by an adjustment in behaviour of the very companies and owners. That will make the resulting behavioural dynamic more difficult to predict. Yet one should not expect that behavioural tendencies will be completely ironed out. One reason is that many of these tendencies take the form of pure economic preference and there is no reason why they should disappear: workers will not stop caring about the way they are treated by their employers. Another one is that some decisions on the labour market are only taken rarely, and therefore do not enjoy the luxury of a direct feedback. Optimal learning might then fail to take place. Behavioural correction or learning itself can be heuristic and result in an error intensification rather than correction. It also seems to be the case that learned behaviour or abilities might not necessarily be transferable between different contexts of one's decision (Loewenstein, 1999).

Further development of the field will be replete with new and detailed data about economic agents' behaviour within firms and outside. The growing popularity of field experiments or randomised controlled trials within economics and the associated further growth in available data will enable a construction of more precise and robust theories of behaviour of workers and managers.

The authors would like to thank Petr Bartoň, Marek Hudík, Pavol Minárik, Ludmila Hadincová, as well as the participants of Science workshop at the FSE UJEP from October 2013, for their valuable comments on previous drafts of the manuscript.

\section{References}

Al-Ubaydli, O., \& List, J. A. (2016). Field Experiments in Markets. National Bureau of Economic Research Working Paper Series, No. 22113. doi: $10.3386 / \mathrm{w} 22113$.

Ariely, D., Gneezy, U., Loewenstein, G., \& Mazar, N. (2009). Large Stakes and Big Mistakes. The Review of Economic Studies, 76(2), 451-469. doi: 10.1111/j.1467937X.2009.00534.x.
Ariely, D., Kamenica, E., \& Prelec, D. (2008). Man's search for meaning: The case of Legos. Journal of Economic Behavior \& Organization, 67(3), 671-677. doi:10.1016/j. jebo.2008.01.004.

Akerlof, G. A., \& Kranton, R. E. (2005). Identity and the Economics of Organizations. The Journal of Economic Perspectives, 19(1), 9-32. doi:10.1257/0895330053147930.

Bandiera, O., Barankay, I., \& Rasul, I. (2005). Social preferences and the response to incentives: Evidence from personnel data. Quarterly Journal of Economics, 120(3), 917962. doi:10.1093/qje/120.3.917.

Barberis, N. C. (2013). Thirty Years of Prospect Theory in Economics: A Review and Assessment. Journal of Economic Perspectives, 27(1), 173-196. doi:10.1257/jep.27.1.173.

Ben-David, I., Graham, J. R., \& Harvey, C. R. (2013). Managerial Miscalibration. The Quarterly Journal of Economics, 128(4), 15471584. doi:10.1093/qje/qjt023.

Bengtsson, N., \& Engström, P. (2013). Replacing Trust with Control: A Field Test of Motivation Crowd Out Theory. The Economic Journal, 124(577), 833-858. doi:10.1111/ecoj.12049.

Bertrand, M., \& Mullainathan, S. (2001). Are CEOs rewarded for luck? The ones without principals are. The Quarterly Journal of Economics, 116(3), 901-932. doi:10.1162/00335530152466269.

Bewley, T. F. (2007). Fairness, Reciprocity, and Wage Rigidity. In P. Diamond \& $\mathrm{H}$. Vartiainen (Eds.), Behavioral Economics and Its Applications (pp. 157-194). Princeton: Princeton University Press.

Bloom, N., Sadun, R., \& Van Reenen, J. (2012). The Organization of Firms Across Countries. The Quarterly Journal of Economics, 127(4), 1663-1705. doi:10.1093/qje/qje029.

Camerer, C. F., Babcock, L., Loewenstein, G., \& Thaler, R. (1997). Labor supply of New York City cabdrivers: One day at a time. The Quarterly Journal of Economics, 112(2), 407441. doi:10.1162/003355397555244.

Camerer, C. F., \& Malmendier, U. (2007). Behavioral Economics of Organization. In P. Diamond \& H. Vartiainen (Eds.), Behavioral Economics and Its Applications (pp. 235-290). Princeton: Princeton University Press.

Croson, R., \& Gneezy, U. (2009). Gender differences in preferences. Journal of Economic Literature, 47(2), 448-474. doi:10.1257/ jel.47.2.448. 
Dahl, M. S., Dezső, C. L., \& Ross, D. G. (2012). Fatherhood and Managerial Style: How a Male CEO's Children Affect the Wages of His Employees. Administrative Science Quarterly, 57(4), 669-693. doi:10.1177/0001839212466521.

DellaVigna, S. (2009). Psychology and Economics: Evidence from the Field. Journal of Economic Literature, 47(2), 315-372. doi:10.1257/jel.47.2.315.

Ellingsen, T., \& Johannesson, M. (2007). Paying respect. The Journal of Economic Perspectives, 21(4), 135-150. doi:10.1257/ jep.21.4.135.

Farber, H. S. (2015). Why you Can't Find a Taxi in the Rain and Other Labor Supply Lessons from Cab Drivers. The Quarterly Journal of Economics, 130(4), 1975-2026. doi:10.1093/qje/qjv026.

Falk, A., \& Fehr, E. (2003). Why labour market experiments? Labour Economics, 10(4), 399-406. doi:10.1016/S0927-5371(03)00050-2.

Fehr, E., Goette, L., \& Zehnder, C. (2009). A Behavioral Account of the Labor Market: The Role of Fairness Concerns. Annual Review of Economics, 1(1), 355-384. doi:10.1146/ annurev.economics.050708.143217.

Fehr, E., \& Götte, L. (2007). Do Workers Work More if Wages Are High? Evidence from a Randomized Field Experiment. The American Economic Review, 97(1), 298-317. doi:10.1257/ aer.97.1.298.

Gneezy, U., Meier, S., \& Rey-Biel, P. (2011). When and why incentives (don't) work to modify behavior. The Journal of Economic Perspectives, 25(4), 191-209. doi:10.1257/ jep.25.4.191.

Graham, J. R., Harvey, C. R., \& Puri, M. (2013). Managerial attitudes and corporate actions. Journal of Financial Economics, 109(1), 103-121. doi:10.1016/j.jfineco.2013.01.010.

Harbring, C., Irlenbusch, B., Kräkel, M., \& Selten, R. (2007). Sabotage in corporate contests - an experimental analysis. International Journal of the Economics of Business, 14(3), 367-392. doi:10.1080/13571510701597445.

Henrich, J., Heine, S. J., \& Norenzayan, A. (2010). The weirdest people in the world? Behavioral and Brain Sciences, 33(2-3), 61-83. doi:10.1017/S0140525X0999152X.

Herbst, D., \& Mas, A. (2015). Peer effects on worker output in the laboratory generalize to the field. Science, 350(6260), 545-549. doi:10.1126/science.aac9555.
Hoogendoorn, S., Oosterbeek, H., \& Van Praag, M. (2013). The impact of gender diversity on the performance of business teams: Evidence from a field experiment. Management Science, 59(7), 1514-1528. doi:10.1287/ mnsc. 1120.1674.

Houdek, P. (2016). What comes to a manager's mind: Theory of local thinking. Journal of Management Inquiry, 25(4), 359-366. doi:10.1177/1056492616640380.

Houdek, P., \& Koblovský, P. (2016). Přehled oboru behaviorální finance a organizace. Acta Oeconomica Pragensia, 24(2), 33-45. doi:10.18267/j.aop.527.

Hudík, M. (2012). When X Becomes X': Sameness and the Internal Consistency of Choice. Retrieved from: http://papers.ssrn.com/ sol3/papers.cfm?abstract_id=2177207.

Chen, K. P. (2003). Sabotage in Promotion Tournaments. Journal of Law, Economics, and Organization, 19(1), 119-140. doi:10.1093/ jleo/19.1.119.

Imas, A. (2016). The Realization Effect: Risk-Taking after Realized versus Paper Losses. American Economic Review, 106(8), 2086-2109. doi:10.1257/aer.20140386.

Kahneman, D., Knetsch, J. L., \& Thaler, R. (1986). Fairness as a constraint on profit seeking - Entitlements in the market. American Economic Review, 76(4), 728-741.

Kahneman, D., \& Tversky, A. (1979). Prospect Theory - Analysis of Decision under Risk. Econometrica, 47(2), 263-291. doi:10.2307/1914185.

Kamenica, E. (2012). Behavioral economics and psychology of incentives. Annual Review of Economics, 4(1), 427-452. doi:10.1146/ annurev-economics-080511-110909.

Köszegi, B., \& Rabin, M. (2006). A model of reference-dependent preferences. The Quarterly Journal of Economics, 121(4), 11331165. doi:10.1093/qje/121.4.1133.

Krueger, A. B., \& Mas, A. (2004). Strikes, scabs, and tread separations: Labor strife and the production of defective Bridgestone/ Firestone tires. Journal of Political Economy, 112(2), 253-289. doi:10.1086/381479.

Kube, S., Maréchal, M. A., \& Puppe, C. (2013). Do wage cuts damage work morale? Evidence from a natural field experiment. Journal of the European Economic Association, 11(4), 853-870. doi:10.1111/jeea.12022.

Kube, S., Maréchal, M. A., \& Puppe, C. (2012). The Currency of Reciprocity: 
Gift Exchange in the Workplace. American Economic Review, 102(4), 1644-1662. doi:10.1257/aer.102.4.1644.

Kuběna, A. A., Houdek, P., Lindová, J., Príplatová, L., \& Flegr, J. (2014). Justine Effect: Punishment of the Unduly Self-Sacrificing Cooperative Individuals. PLOS ONE, 9(3), e92336. doi:10.1371/journal.pone.0092336.

List, J. A., \& Rasul, I. (2011). Chapter 2 Field Experiments in Labor Economics. In A. Orley \& C. David (Eds.), Handbook of Labor Economics (Vol. 4, Part A, pp. 103-228). Amsterodam: Elsevier.

Malmendier, U., \& Tate, G. (2005). CEO Overconfidence and Corporate Investment. The Journal of Finance, 60(6), 2661-2700. doi:10.1111/j.1540-6261.2005.00813.x.

Malmendier, U., \& Tate, G. (2008). Who makes acquisitions? CEO overconfidence and the market's reaction. Journal of Financial Economics, 89(1), 20-43. doi: 10.1016/j. jfineco.2007.07.002.

Malmendier, U., \& Tate, G. (2009). Superstar CEOs. The Quarterly Journal of Economics, 124(4), 1593-1638. doi:10.1162/ qjec.2009.124.4.1593.

Mas, A. (2006). Pay, reference points, and police performance. Quarterly Journal of Economics, 121(3), 783-821. doi:10.1162/ qjec.121.3.783.

Mas, A., \& Moretti, E. (2009). Peers at Work. The American Economic Review, 99(1), 112-145. doi:10.1257/aer.99.1.112.

Parboteeah, K. P., Addae, H. M., \& Cullen, J. B. (2005). National culture and absenteeism: An empirical test. International Journal of Organizational Analysis, 13(4), 343-361. doi:10.1108/eb029011.

Pascual-Ezama, D., Prelec, D., \& Dunfield, D. (2013). Motivation, money, prestige and cheats. Journal of Economic Behavior \& Organization, 93(September), 367-373. doi:10.1016/j.jebo.2013.03.015.

Pedace, R., \& Smith, J. K. (2013). Loss aversion and managerial decisions: Evidence from major league baseball. Economic
Inquiry, 51(2), 1475-1488. doi:10.1111/j.14657295.2012.00463.x.

Rabin, M. (1998). Psychology and economics. Journal of Economic Literature, 36(1), 11-46.

Rusinova, K., \& Houdek, P. (2013). Physicians looking in the mirror: how we may influence the end-of-life decisions of surrogates. Critical Care Medicine, 41(7), 1814-1815. doi:10.1097/CCM.0b013e3182913395.

Stafford, T. M. (2015). What Do Fishermen Tell Us That Taxi Drivers Do Not? An Empirical Investigation of Labor Supply. Journal of Labor Economics, 33(3), 683-710. doi:10.1086/679682.

Vranka, M. A., \& Houdek, P. (2015). Many Faces of Bankers' Identity: How (not) to study dishonesty. Frontiers in Psychology, 6(302). doi:10.3389/fpsyg.2015.00302.

Jan Evangelista Purkyně University in Ústí nad Labem

Faculty of Social and Economic Studies Department of Economics and

University of Economics in Prague Faculty of Business Administration Department of Management and Charles University in Prague Faculty of Science Department of Philosophy and History of Science petr.houdek@ujep.cz

Ing. Mgr. Petr Koblovský, Ph.D., LL.M. et. LL.M., MIM. Jan Evangelista Purkyně University in Ústí nad Labem

Faculty of Social and Economic Studies and Institute for Behavioral and Economic Studies, Prague petr.koblovsky@aya.yale.edu 


\title{
BEHAVIOURAL ECONOMICS OF ORGANIZATION: EMPLOYEES AND MANAGERS
}

\author{
Petr Houdek, Petr Koblovský
}

This short perspective article presents an overview of empirical evidence on the behavioural organizational economics on the basis of the extended standard model of worker's behaviour. The advancements of behavioural economics theories, new detailed and structured data on actions of economic actors, and increasingly used fields experiments provide a strong basis for the creation of more precise and more robust models of the behaviour of employers and employees. In this article we analyse 4 stylized extensions of standard model of worker's behaviour. Firstly, we give several examples of worker's reference dependent decision-making. Secondly, we utilize Akerlof's hypothesis on the relationship between an employer and an employee which is as predicted very reciprocal, similarly to the gifts exchange paradigm. We show that the more the employee thinks $s / h e$ is trusted by the employer, the harder and more efficiently s/he works. Thirdly, we show several instances of the importance of extrinsic and intrinsic motivation in employees and how those two motivations interfere with each other and crowd each other out in some situations. The research shows that meaningfulness of the work can be a significant driver of the employees' efficiency as well. In the last section devoted to employees we provide evidence on the impacts of relative performance compensation on cooperation, reciprocity, and sabotage in firms. The last part is devoted to analysing behavioural regularities of managers in their day-to-day decision-making. The overview briefly expands particularly on their over-optimism and on their possibly undeserved remuneration resulting from random events and market changes rather than from the managerial skills. The article concludes by proposing possible directions for further field research.

Key Words: Behavioural economics, firm culture, field experiments, gift exchange, hubris, CEO, intrinsic and extrinsic motivation, loss aversion, reference-dependence model, reciprocity, social preferences, wage, labour.

JEL Classification: C93, D86, J41, M54.

DOI: 10.15240/tul/001/2017-1-001 